\title{
FAKTOR YANG MEMPENGARUHI KEPUASAN PELANGGAN DI LEMBAGA KURSUS PENDIDIKAN SEKAR KOTA TEGAL
}

\author{
YUNIETI UTAMIE \\ Universitas Muhammadiyah Purwokerto \\ Email : sekaryunie@gmail.com
}

\begin{abstract}
ABSTRAK
Kepuasan pelanggan dapat dipengaruhi dari beberapa faktor. Ini dapat menjadi penilaian bagi suatu lembaga ataupun usaha-usaha tertentunya. Kepuasan pelanggan sering kali kita dapat dari pelanggan yang mungkin berkunjung pada lembaga atau perusahaan kita. Pada penelitian ini bertujuan agar dapat mengetahui seberapa pelanggan merasa puas dengan kita atas pelayanan serta hal hal lain yang diberikan. Dengan begitu kita akan selalu membenahi atau meningkatkan pelayanan di lembaga, serta dari pihak lembaga akan mengerti dari para pelanggan mereka akan menilai dari segi mana mereka puas pada usaha kita. Pada Lembaga kursus pendidikan (LKP) Sekar Kota tegal ada beberapa faktor yang mempengaruhi kepuasan pelanggan contohnya dari segi harga, fasilitas, serta kualitas pelayanan. Metode penelitian yang digunakan adalah penelitian kuantitatif dan perhitungan spss dengan metode survey, dengan memberikan instrument kepada para pesrta didik dan para alumni lembaga untuk mendapatkan penilaian tentang kepuasan pelangan di Lembaga Kursus pendidikan Sekar Kota tegal. Dari hasil survey dan perhitungan spss secara parsial dan simultan Harga, Fasilitas dan Kualitas Pelayanan memberkan pengaruh terhadap kepuasan pelanggan. Sehingga dengan kata lain ketiga dari faktor teresebut memiliki pengaruh terhadap kepuasan pelanggan di Lembaga Kursus Pendidikan Sekar Kota Tegal.
\end{abstract}

Kata Kunci : Harga, Fasilitas,Kualitas pelayanan. Dan Kepuasan pelanggan

\section{PENDAHULUAN}

Di bidang kursus dan pelatihan era gobalisasi yang berkembang pesat, membuat persaingan antar lembaga semakin ketat dalam upaya meningkatkan kualitas peserta didik yang berkompeten. Sehingga lembaga yang bergerak di bidang jasa pelatihan dituntut baik pengelola maupun tenaga instrukturlebih berkompetensi dibidangnya. Sebagai motor penggerak pelaksanaan dalam kursus dan pelatihan diharapkan pengelola lembaga mampu menyukseskan pendidikan dari berbagai segi atau cara. Juga mampu memaksimalkan kompetensinya sehingga dapat menentukan keberhasilan suatu lembaga kursus dan pelatihan dengan baik.Serta mampu memaksimalkan keberhasilan kompetensi sebuah lembaga kursus dan pelatihan dalam kecakapan mengelola sumber daya manusia (SDM) dan dalam mengembangkan dimensi lainnya.

Pengelola harus mampu menjadi leader mengarahkan sebuah lembaga kursus dan pelatihan dalam mencapai tujuan. Seluruh komponen dan sarana kursus dan pelatihan idealnya mampu dimaksimalkan dengan baik sesuai standar kursus dan pelatihan. Dalam usaha pengembangan lembaga kursus dan pelatihan, seorang pengelola lembaga harus mampu memerankan tugas pokok dan fungsinya sehingga dapat mempengaruhi keberhasilan sebuah lembaga kursus dan pelatihan dengan cara pengelolaan lembaga yang baik, admistrasi, menyusun rencana strategi sebagai usaha pengembangan dan penyelenggaraan kegiatan yang lebih inovatif.

Pengelola lembaga kursus dan pelatihan memiliki kewenangan tertinggi dalam manajemen lembaga itu sendiri maupun tenaga instruktur dan serta menentukan kebijaksanaan yang tentu saja sangat berpengaruh kinerja lembaga. Serta memiliki kemampuan dan ketrampilan untuk memimpin sebuah lembaga kursus dan pelatihan. Sebuah lembaga kursus dan pelatihan selain dituntut dalam berkompetensi dibidangnya, pengaruh harga, fasilitas dan kualitas pelayanan juga mempengaruhi kepuasan pelanggan dalam suatu lembaga. Lembaga kursus dan pelatihan (LKP) Sekar merupakan salah satu usaha bergerak dibidang jasa tata rias 
pengantin wanita dan pria. Selaiin memberikan kursus tata arias pengantin, LKP Sekar jugs memberikan kursus dan pelatihan hantaran pengantin dan potong rambut yang banyak diminati masyarakat.

Pentingnya keulitas pelayanan untuk menarik pelanggan merupakan acuan pada harga karena pada dasarnya harga juga dapat dikatakan sebagai suatu ukuran alat tukar agar memperoleh hak kepemilikan atau penggunan suatu produk ataupun jasa. Hal ini menunjukan bahwa konsumen akan selektif dalam memilih salah satu dari banyaknya alternatif yang sesuai dengan keinginan dan kebutuhan, ini bisa menjadi salah satu faktor yang sangat berpengaruh untuk kepuasan pelanggan (Anindhyta Budiarti, Fifin Anggaraini, 2020). Selain dari faktor harga yang mempengaruhui kepuasan pelanggan, dalam faktor lainpun yakni fasilitas, fasilitas itu sendiri merupakan segala sesuatu yang sengaja disediakan oleh penyedia jasa untuk dipakai serta dinikmati oleh konsumen yang bertujuan meberikan tingkat kepuasan yang maksimal. Fasilitas merupakan segala sesuatu yang bersifat peralatan fisik yang disedikan oleh pihak penyedia jasa untuk mendukung kenyamanan konsumen (Andi Muhammad irfan, 2018).

Dalam hal ini pelanggan akan merasa puas apabila harapanya terpenuhi dan akan sangat puas jika harapan pelanggan terlampaui. Harapan itu biasanya bertumpu pada sebuah salah satu faktor yakni hargapada sebuah lembaga yang notabenya lebih memberikan implikasi yang sangat berpengaruh dalam kepuasan masing-masing..Sebaliknya jika hasil akhir pada pelanggan tidak sesuai dengan harapan pelanggan, maka pelanggan merasakan ketidak puasan( Yuliantini, 2021).

Menurut hasil penelitian yang dilakukan oleh ( Yulianti, 2021) bahwa harga dapat mempengaruhi kepuasan pelanggan secara parsial. Peneliti laipun mendapatkan hasil bahwa Fasilitas memiliki pengaruh yang signifikan terhadap kepuasan pelanggan (Andi Muhammad Irfan, 2018). Sedangkan penelitian yang dilakukan oleh (Rama joko Darmawan, Budhi Satrio, 2017) menyatakan hasil penelitianya tentang kualitas pelayanan yang berpengaruh terhadap kepuasan pelayanan.

Dalam memberikan penilaian terhadap kepuasan pelanggan di lembaga kursus pendidikan ini yang berdampak pada perkembangan dari lembaga adanya faktor yang mempengaruhinya, beberapa faktornya yaitu harga, fasilitas, dan kualitas pelayanan.

Penelitian ini dilakukan dengan maksud untuk menganalisis faktor apa saja yang dapat mempengaruhi kepuasan pelanggan di lembaga kursus pendidikan Sekar Kota Tegal. Karena adanya penurunan jumlah peserta didik kursus saat pandemi covid 19 di lembaga kursus pendidikan Sekar Kota Tegal. Sehingga dapat benahi untuk di evaluasi kembali dari faktor faktor tersebut dengan tingkat kepuasan pelanggan yang maksimal pada lembaga kursus pendidikan.

Dengan adanya dilakukan penelitian ini diharapkan akan dapat dijadikan acuan dalam mengatasi penurunan peserta didik pada lembaga kursus pendidikan. Sehingga untuk kedepannya dapat memberikan pelayanan yang maksimal untuk para peserta didik. Selain itu dapat dijadikan pedoman sebagai dalam merencanakan strategi dalam menarik pelanggan/masyarakat yang akan kursus di lembaga kursus pendidikan Sekar.

\section{METODE PENELITIAN}

Penelitian ini menggunakan desain penelitian deskriptif kuantitatif dengan metode survey dengan perhitungan analisis data statistik Deskriptif. Penelitian kuantitatif bertujuan untuk melakukan pengukuran dalam melihat hubungan antara yang fundamental anatara pengamatan empiris dengan hasil data secara kuantitatif. Uji yang akan dihitung meliputi statistik deskriptif, Uji asumsi klasik dan Uji regresi linier berganda. Pada penelitian ini Peneliti akan melakukan survey dengan memberikan pertanyaan yang sama kepada responden yang dijadikan sampel pada penelitian ini. Populasi dalam penelitian ini adalah peserta didik dan alumni dari LKP Sekar Kota Tegal. Populasi yang nanti akan digunakan sebanyak 120 responden dari para peserta didik dan alumni LKP Sekar. 


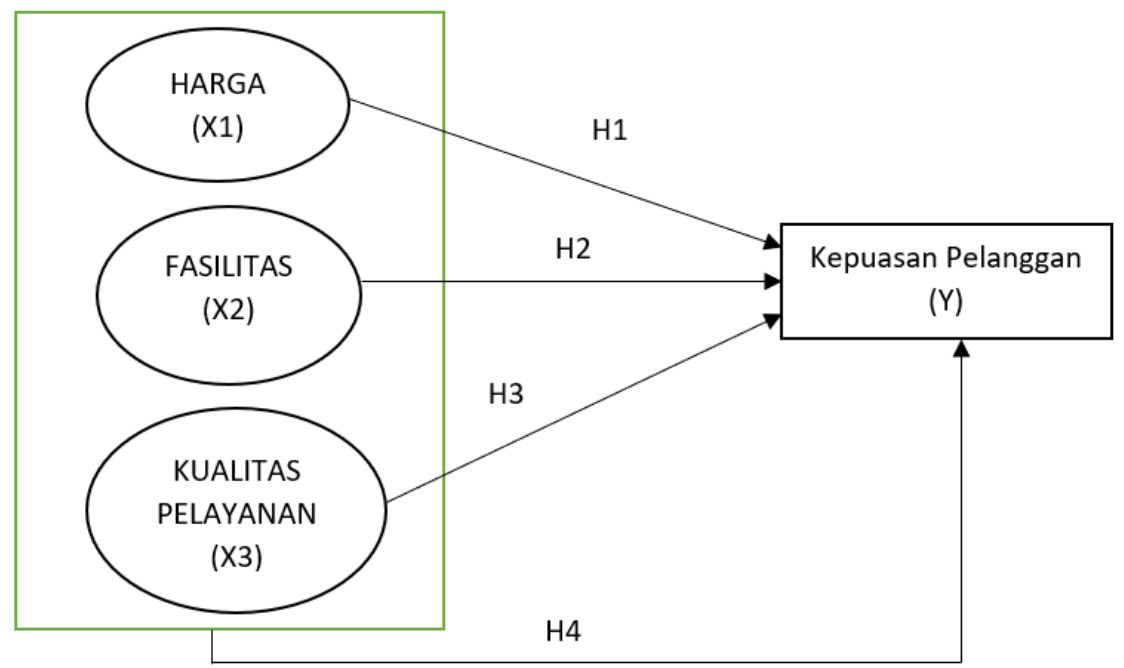

Gambar 1. Kerangka Teoritis

Hipotesis

H1 : Harga Berpengaruh Terhadap Kepuasan Pelanggan

H2 : Fasilitas Berpengaruh Terhadap Kepuasan Pelanggan

H3 : Kualitas Pelayanan Terhadap Kepuasaan pelanggan

H4 : Harga, Fasilitas, dan Kualiatas Pelayanan Berpengaruh Terhadap Kepuasan Pelanggan.

\section{HASIL DAN PEMBAHASAN}

Berdasarkan analisis deskriptif yang dilakukan, diperoleh temuan nilai rata-rata (mean) dari setiap variabel harga, fasilitas, kualitas pelayanan dan kepuasan pelanggan ditunjukan pada tabel berikut

Tabel 1. Descriptive Statistics

\begin{tabular}{|c|c|c|c|c|c|c|c|}
\hline & $\mathrm{N}$ & Range & $\underset{\mathrm{m}}{\mathrm{Minimu}}$ & $\begin{array}{c}\text { Maximu } \\
\mathrm{m}\end{array}$ & Mean & $\begin{array}{c}\text { Std. } \\
\text { Deviation }\end{array}$ & Variance \\
\hline TotalX1 & 120 & 8 & 32 & 40 & 35,14 & 1,848 & 3,417 \\
\hline TotalX2 & 120 & 19 & 21 & 40 & 34,91 & 2,126 & 4,521 \\
\hline TotalX3 & 120 & 8 & 32 & 40 & 35,31 & 1,855 & 3,442 \\
\hline TotalY1 & 120 & 8 & 32 & 40 & 35,42 & 1,977 & 3,909 \\
\hline $\begin{array}{l}\text { Valid N } \\
\text { (listwise) }\end{array}$ & 120 & & & & & & \\
\hline
\end{tabular}

Pada tabel diatas menunjukan bahwa harga, fasilitas, kualitas pelayanan dan kepuasan pelanggan memilik rata-rata yang sepadan atau baik.

Uji asumsi klasik

\section{Uji Normalitas}

Model regresi yang baik seharusnya memiliki residu yang berdistribusi secara normal. Untuk menguji apakah distribusi data normal atau tidak cara untuk mendeteksinya, yaitu dengan uji statistic dengan dapat digunakan uji kolmogorov-smirnov, apabila nilai profitabilitas yang diperoleh lebih besar dari 0,05 dapat disimpulkan bahwa residu dalam model regresi berdistrobusi secara normal. 
Tabel 2. Uji Normalitas

\section{One-Sample Kolmogorov-Smirnov Test}

\begin{tabular}{llr} 
& & $\begin{array}{r}\text { Unstandardiz } \\
\text { ed Residual }\end{array}$ \\
\hline $\mathrm{N}$ & Mean & 120 \\
\hline Normal Parameters & Stb &, 0000000 \\
\cline { 2 - 3 } & $\begin{array}{l}\text { Std. } \\
\text { Deviation }\end{array}$ & 1,52582991 \\
\hline $\begin{array}{l}\text { Most Extreme } \\
\text { Differences }\end{array}$ & Absolute &, 055 \\
\cline { 2 - 3 } & Positive &, 055 \\
\cline { 2 - 3 } Test Statistic & Negative &,- 044 \\
\hline Asymp. Sig. (2-tailed) & &, 055 \\
\hline a. Test distribution is Normal & &, $200^{\mathrm{c}, \mathrm{d}}$ \\
\hline
\end{tabular}

a. Test distribution is Normal.

b. Calculated from data.

c. Lilliefors Significance Correction.

$\mathrm{d}$. This is a lower bound of the true significance.

Berdasarkan uji kolmogrov smirnov terlihat bahwa nilai signifikan sebesar 0,200 lebih besar dari 0.05. Maka dapat disimpulkan bahwa data berdistribusi normal.

\section{Uji Multikorelineritas}

Dalam mendeteksi masalah multikolinieritas dapat dilihat dari nilai VIF. Apabila nilai VIF lebih kurang dari 10, dapat disimpulkan bahwa model terbebas dari masalah multikolinearitas.

\begin{tabular}{|c|c|c|}
\hline \multirow[b]{2}{*}{ Model } & \multicolumn{2}{|c|}{$\begin{array}{c}\text { Collinearity } \\
\text { Statistics }\end{array}$} \\
\hline & $\begin{array}{c}\text { Toleran } \\
\text { ce }\end{array}$ & VIF \\
\hline $\begin{array}{l}\text { (Consta } \\
\text { nt) }\end{array}$ & & \\
\hline TotalX1 & 623 & 1,606 \\
\hline TotalX2 & 827 & 1,209 \\
\hline TotalX3 & 642 & 1,557 \\
\hline
\end{tabular}

Berdasarkan tabel diatas dilihat bahwa nilai VIF pada setiap variabel kurang dari 10 . Hasil tersebut menunjukan bahwa tidak terdapat masalah multikorelineritas anatar variabel bebas dalam model.

\section{Uji Heteroskedastisitas}

Uji heteroskedastisitas bertujuan untuk menguju homogenitas varians residu dalam sebuah model regresi. Salah satu cara untuk mendeteksi heteroskedastisitas adalah dengan prediksi variabel terikat (dependen) yaitu ZPRED dengan nilai residualnya (SRESID) 


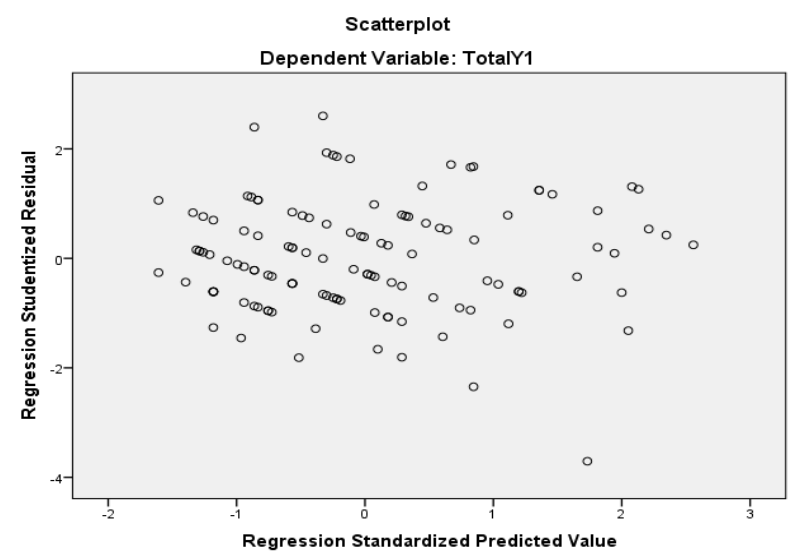

Gambar 2. Uji Heteroskedasitas

Dari gambar diatas dapat dilihat bahwa dalam model tidak terdapat heterokedastisitas karena pada gambar tidak ada pola yang jelas serta titik titik menyebar diatas dan dibawah angka 0 pada sumbu Y. Hal ini menandakan bahwa dalam model, variansi dari residual satu pengamatan ke pengamatan yang lain sama atau konstan. Sehingga asumsi tidak adanya heteroskedastisitas atau adanya homoskedastisitas sudah terpenuhi untuk persamaan regresi.

\section{Analisis Regresi Linier Berganda}

Analisis ini digunakan untuk mengetahui seberapa faktor dari kepuasan pelanggan yaitu Harga (X1), Fasilitas (X2), dan Kualitas Pelayanan (X3) Terhadap Kepuasan Pelanggan (Y).

\begin{tabular}{|c|c|c|c|c|c|c|}
\hline \multicolumn{7}{|c|}{$\begin{array}{l}\text { Tader 4. Anansis Kegrest } \\
\text { Coefficients }^{\mathrm{a}}\end{array}$} \\
\hline \multirow{2}{*}{\multicolumn{2}{|c|}{ Model }} & \multicolumn{2}{|c|}{$\begin{array}{l}\text { Unstandardized } \\
\text { Coefficients }\end{array}$} & \multirow{2}{*}{$\begin{array}{c}\text { Standardized } \\
\text { Coefficients } \\
\text { Beta } \\
\end{array}$} & \multirow[b]{2}{*}{$\mathrm{t}$} & \multirow[b]{2}{*}{ Sig. } \\
\hline & & $\mathrm{B}$ & Std. Error & & & \\
\hline \multirow[t]{4}{*}{1} & (Constant) & 8,199 & 3,254 & & 2,520 &, 013 \\
\hline & Harga &, 136 & ,097 &, 127 & 1,399 &, 164 \\
\hline & Fasilitas &, 100 & 073 & , 108 & 1,366 &, 175 \\
\hline & $\begin{array}{l}\text { Kualitas } \\
\text { Pelayanan }\end{array}$ & ,537 & ,095 &, 504 & 5,632 & ,000 \\
\hline
\end{tabular}

a. Dependent Variable: Kepuasan Pelanggan

Bila hasil perhitungan dari print out komputer dengan bantuan program spss versi 24 dimasukan ke dalam persamaan di atas diperoleh nilai sebesar:

$$
\mathrm{Y}=8,199+0,136(\mathrm{X} 1)+0,100(\mathrm{X} 2)+0,537(\mathrm{X} 3)
$$

Dari persamaan diatas diperoleh koefisien regresi bernilai positif dari Harga (X1), Fasilitas (X2), dan Kualitas Pelayanan (X3) terhadap Kepuasan Pelanggan (Y). Hal ini berarti bahwa:

a. Konstanta sebesar 8,199 dapat diartikan sebelum dipengaruhi variabel Harga (X1), Fasilitas (X2) dan Kualitas Pelayanan (X3), maka Kepuasan Pelanggan positif.

b. Koefisiensi regresi b1 $=0,136$ artinya apabila harga (X1) meningkat maka kepuasan pelanggan (Y) akan meningkat dengan asumsi variabel Fasilitas (X2) dan Kualitas Pelayanan (X3) dianggap konstan.

c. Koefisiensi regresi b2 $=0,100$ artinya apabila Fasilitas meningkat maka kepuasan pelanggan (Y) Akan meningkat dengan asumsi variabel Harga (X1) dan Kualitas Pelayanan dianggap konstan.

d. Koefisinesi regresi $\mathrm{b} 3=0,537$ artinya apabila kualitas pelayanan meningkat maka kepuasan pelanggan (Y) Akan meningkat dengan asumsi varibel Harga (X1) dan Fasilitas (X2) dianggap konstan. 


\section{Koefisien determinasi $\left(R^{2}\right)$}

Analisis ini bertujuan untuk mengukur seberapa jauh kemampuan model dalam menerangkan variasi variabel dependennya Nila $\mathrm{R}^{2}$ yang mendekati satu berarti varibelvariabelnya indepenya memberikan hampir semua informasi yang dibutuhkan untuk memprediksi variasi variabel dependen.

\section{Tabel 5. koefisien Determinasi $\left(\mathbf{R}^{2}\right)$ Model Summary}

\begin{tabular}{ll|r|r|r} 
Model & R & R Square & $\begin{array}{c}\text { Adjusted R } \\
\text { Square }\end{array}$ & $\begin{array}{l}\text { Std. Error of } \\
\text { the Estimate }\end{array}$ \\
\hline 1 &, $636^{\mathrm{a}}$ &, 404 &, 389 & 1,545 \\
\hline
\end{tabular}

a. Predictors: (Constant), Kualitas Pelayanan, Fasilitas, Harga

Berdasarkan tabel diatas tampak bahwa dari hasil perhitungan diperoleh adjusted $\mathrm{R}$ square $\left(\mathrm{R}^{2}\right)$ sebesar 0,389 adengan kata lain hal ini menunjukan bahwa besar presentase variasi kepuasan pelanggan yang bisa dijelaskan oleh variasi ketiga variabel bebas yaitu Harga, Fasilitas, dan Kualitas pelayanan adalah sebesar $38.9 \%$ sedangkan sisanya sebesar $\left(1-\mathrm{R}^{2}\right)=$ $61,1 \%$ dijelaskan oleh sebab lain diluar model.

Harga yang merupakan satu-satunya unsure bauran pemasaran yang seringkali dijadikan sebagai bahan pertimbangan bagi konsumen dalam melakukan pembelian tiak bisa dikesampingkan oleh perusahaan (Nuruddin Mahmud, 2021). Banyak perusahaan mengadakan pendekatan terhadap penentuan harga berdassarkan tujuan yang hendak dicapainya. Adapun tujuan tersebut dapat meningktakan penjulan, mempertahankan market share serta mempertaruhkan stabilitas harga, dan mencapai laba yang maksimum.

Fasilitas merupakan salah satu faktor yang menunjukan kepuasan konsumen. Semakin baik fasilitas yang ditawarkan maka semakin tinggi kepuasan konsumen. Fasilitas juga merupakan segala sesuatu yang memudahkan konsumen dalam usaha yang bergerak dibidang jasa, maka segala fasilitas yang ada yaitu kondisi fasilitas, kelengkapan, desain interior dan eksterior serta kebersihan fasilitas harus diperhatikan terutama yang berkaitan erat dengan apa yang dirasakan atau didapat konsumen secara langsung.

Kualitas pelayanan merupakan salah satu faktor dari kepuasan pelanggan, kualitas pelayanan merupakan segala bentuk aktivitas yang dilakukan oleh perusahaan guna memenuhi harapan konsumen. Menurut Cristina, 2013 ( Anindyta Budiarti, Fifin Anggraini, 2020) merupakan preseptif konsumen dalam jangka panjang dan merupakan evaluasi kognitif dari jasa transfer, maksudnya kualitas pelayanan yang baik akan memberikan dapak positif bagi perusahaan karean kualitasakan menjadi penilaian konsumen.

Jadi faktor yang dapat mempengaruhi kepuasan pelanggan di LKP Sekar Kota Tegal yaitu Harga, fasilitas, Kualitas pelayanan. Dengan diketahuinya faktor-faktor yang mempengaruhi kepuasan pelanggan maka dapat dilakukan perubah perubahan yang dapat membuat para peserta didik dan alumni akan merasa puas dengan hasil maksimal yang diberikan oleh pihak LKP.

\section{KESIMPULAN}

Berdasarkan hasil penelitian "Faktor Yang Mempengaruhi Kepuasan Pelanggan Di LKP Sekar Kota Tegal" dapat disimpulkan bahwa secara parsial parsial dan simultan harga, fasilitas dan kualitas pelayanan memberIkan pengaruh terhadap kepuasan pelanggan. Sehingga dengan kata lain ketiga dari faktor teresebut memiliki pengaruh terhadap kepuasan pelanggan di lembaga kursus pendidikan Kota Tegal. 


\section{DAFTAR PUSTAKA}

Anggraini, Fifin dan Anindhyta Budiarti. (2020). Pengaruh Harga, Promosi, Dan Kualitas Pelayanan Terhadap Loyalitas Pelanggan Dimediasi Kepuasan Pelanggan Pada Konsumen Gojek.

Irfan, Muhammad Andi (2018). Pengaruh Kualitas Pelayanan, Harga Dan Fasilitas Yang Diberikan Kenari Waterpark Bontang Terhadap Tingkat Kepuasan Pelanggan. jurnal ekonomi islam. Vol. 9, No 2, Desmber 2018. ISSN: 2579-6453

Isnaini, Siti. (2018). Pengaruh Harga Dan Lokasi Terhadap Kepuasan Pelanggan Pada Lembaga Kursus Dan Pelatihan Lembaga Kursus Pendidikan Andini Jombang. journal of Business and innovation Management.Volume 1 Nomor 1, Oktober 2018.

Mahmud, Nuruddin. (2021). Pengaruh Harga, Kualitas Produk, Dan Kualitas Pelayanan Terhadap Kepuasan Pelanggandi Transmart Setiabudi Semarang. Jurnal Ekonomi dan Bisnis STIE Anindyaguna. Vol. 3, No. 1, April 2021. ISSN: 2746-1173.

Yuliantini. (2021). Pengaruh Produk, Harga Dan Promosi Terhadap Citra Merek Serta Implikasinya Pada Kepuasan Pelanggan Di Busana Muslim Alisha Kota Bandung. 